\title{
A usabilidade de tarefas típicas de seleção do destino em sistemas de navegação GPS automotivos
}

\author{
Manuela Quaresmaa,* ${ }^{a}$ Anamaria de Moraes $^{\mathrm{b}}$ \\ a,*info@manuelaquaresma.com, PUC-Rio, Brasil \\ bmoraergo@puc-rio.br, PUC-Rio, Brasil
}

\begin{abstract}
Resumo
O sistema de navegação GPS automotivo é um sistema veicular que auxilia o motorista, através de mapas e indicadores de manobra, o caminho que ele deve percorrer até o seu destino. Este artigo apresenta um estudo sobre a usabilidade de tarefas típicas de seleção do destino em três sistemas vendidos no Brasil, com métodos de entrada de dados e interfaces distintos. A pesquisa teve como objetivo avaliar se problemas de usabilidade também ocorriam em navegadores brasileiros. Para tanto, foram aplicados testes de usabilidade com usuários experientes e não experientes, com o intuito de medir a eficácia, a eficiência e a satisfação de uso (métricas de usabilidade) das três interfaces. Com os resultados dos testes, pôde-se observar diversos problemas de usabilidade no projeto das interfaces avaliadas. Também, com base neles, foi possivel sugerir soluções adequadas para a organização e navegação de menus e comandos.
\end{abstract}

Palavras-chave

Sistemas de navegação GPS. Usabilidade. Interação humano-computador. Ergodesign.

\section{Introdução}

0 avanço da tecnologia da computação em sistemas veiculares tem se mostrado bastante intenso nos últimos anos. Hoje, existem três tipos de sistemas disponíveis em automóveis: os sistemas avançados de assistência ao motorista, os sistemas de informação e os sistemas de entretenimento. Dentre esses, os navegadores GPS são os mais difundidos no mercado brasileiro.

Apesar de já existirem há algumas décadas, nos últimos anos os GPSs automotivos evoluíram bastante, principalmente devido ao constante mapeamento das cidades e à inserção de novas tecnologias, como os displays de LCD coloridos e as telas touch-screen. Essa evolução pôde ser acompanhada em países da América do Norte e da Europa, onde a difusão desse tipo de sistema foi bem ampla.

No Brasil, até março de 2006, com a publicação da Resolução no 190/06 do Contran (BRASIL, 2006), não se ouvia falar desse sistema inserido em nossos veículos de passeio. Antes dessa data os sistemas de navegação tinham sido proibidos para o motorista em veículos brasileiros com a Resolução no 153/03
(BRASIL, 2003), que proibia qualquer equipamento capaz de gerar imagens em movimento. Acredita-se que essa primeira resolução veio com o intuito de proibir o uso de equipamentos como o DVD, mas acabou incluindo os sistemas de navegação, pois estes também geram imagem de mapas em movimento. No entanto, devido a fortes pressões do mercado, o Conselho Nacional de Trânsito substituiu a Resolução n 153/03 pela n 190/06, liberando o uso dos sistemas de navegação, contanto que este apresentasse apenas símbolos e/ou áudio para orientar. Essa resolução não chegou a liberar, a princípio, os sistemas como eles eram em países estrangeiros, mas foi suficiente para que em menos de um ano surgissem pelo menos dez tipos de navegadores diferentes. Em 2007, o Contran finalmente libera os sistemas com as imagens de mapas em movimento com a Resolução no 242/07 (BRASIL, 2007), revogando a resolução anterior. Até o final de 2009 já era possível ver mais de 50 navegadores diferentes sendo vendidos no mercado brasileiro. 
Entretanto, a interação do usuário com esse sistema vem sendo alvo de muitas pesquisas nas áreas da ergonomia cognitiva e interação humanocomputador, pois o uso desses sistemas tem apresentado vários problemas de usabilidade. Esses problemas na interação motorista-sistema podem causar distrações ao motorista e, consequentemente, influenciar na tarefa de dirigir. (2003),

De acordo com Nowakowski, Green e Tsimhoni

[...] um sistema de navegação bem projetado pode evitar manobras erradas, reduzir o tempo de viagem e, com esperança, aliviar alguma carga de trabalho do motorista. Entretanto, má usabilidade pode colocar os motoristas na direção errada, aumentar sua carga de trabalho e levá-los a fazer manobras não seguras.

\section{Os sistemas de navegação GPS automotivos}

0 sistema de navegação GPS é um sistema de informação veicular que tem o objetivo principal de guiar o motorista até um destino determinado. Através da antena GPS, o dispositivo localiza a posição do veículo num mapa inserido no banco de dados do sistema. Para guiar até o destino desejado, o motorista entra com os dados do endereço no sistema para que ele calcule a rota. A inserção desses dados é feita, normalmente, por botões físicos ou virtuais numa tela touch-screen. Com a rota calculada, o sistema guia o motorista com o veículo em movimento através de mapas, instruções de voz e indicadores (símbolos, gráficos e mensagens), por todo o percurso até chegar ao destino.

Os mapas geralmente são apresentados numa vista de topo da região (em 2D) ou perspectiva (em 3D), em diversas escalas e com vários níveis de aproximação (zoom), podendo apresentar somente a via em que o veículo se movimenta até um grupo de vias. A apresentação do mapa pode ser fixada no sentido Norte ou pode acompanhar o movimento do veículo, neste caso mostrando sempre o que vem à frente na parte de cima da tela. Além do mapa, na tela são apresentados indicadores, como símbolos para guiar nas manobras de condução do automóvel, informações da rota requerida, distâncias percorridas e remanescentes, tempo de viagem estimado, velocidade do veículo etc.

Para fazer funcionar o equipamento, o usuário insere o endereço do destino a que pretende chegar, indicando a cidade, a rua e o número da edificação ou indicando um ponto de interesse (conhecido como POI - Point of Interest) existente no banco de dados do sistema, sempre informando também se quer a rota mais rápida - considerando as vias expressas - ou o percurso mais curto em quilometragem - considerando vias urbanas. A partir daí o sistema calcula a rota, apresenta o itinerário e guia o motorista, passo a passo, até o seu destino.

Nos sistemas disponíveis atualmente, a entrada de dados do destino pode ser feita através de controles no equipamento (tipo joystick) ou comandos na tela (touch-screen), assim como é possível entrar com os dados por fala, em aparelhos com reconhecimento de voz. Como saídas, o sistema apresenta as informações na tela e/ou através de gravações de voz, guiando o motorista passo a passo falando, por exemplo, "vire à direita", "vire à esquerda" ou "entre na terceira rua à direita em 750 metros".

Em geral, os dados das vias e dos pontos de interesse (POI) dos mapas ficam armazenados em HDs (hard disks) do próprio equipamento e são referentes aos dados do país em que o equipamento ou o veículo foi comprado. Porém, é possível inserir dados de outros países e fazer atualizações dos dados, através da internet ou de mídias como CDs, DVDs (conectando o navegador a um computador) e memórias flash removíveis.

Em alguns veículos, em situações que se perde o sinal do GPS, como o confinamento em construções urbanas e/ou túneis, existem sensores acoplados ao motor do veículo e um giroscópio capazes de calcular as distâncias e o movimento do veículo com confiabilidade, mantendo o guia da rota sem atrasos e erros. Naqueles que não possuem esses sensores nem giroscópio, o navegador após a perda do sinal recalcula a rota a partir do ponto em que o veículo se encontra no momento da retomada do sinal. Ocorre da mesma maneira quando o motorista erra ou muda o caminho apresentado pelo navegador. Ao reconhecer a mudança da rota o sistema recalcula o itinerário a ser percorrido para o mesmo destino.

Além da função de guiar o motorista de um ponto a outro, os navegadores mais modernos fornecem mais funções associadas a outras tecnologias. Conectado a uma rede sem fio (tipo GSM - rede de telefonia móvel digital), o navegador identifica áreas onde o tráfego está congestionado e sugere outra rota, que pode ser alterada ou não pelo motorista.

Outra função bem interessante que pode ser encontrada nos bancos de dados dos navegadores são as localizações de serviços mais próximos ao itinerário e à posição do veículo - pontos de interesse. Os serviços mais comuns disponíveis são os postos de gasolina, caixas eletrônicos, restaurantes 
e aeroportos. No mesmo tipo de identificação é possível avisar a proximidade de radares de velocidade, inclusive informando ao motorista qual é a velocidade máxima da via.

Outro recurso também associado à conexão sem fio, como a bluetooth, está na conexão com telefones celulares. 0 equipamento reconhece o telefone celular do usuário permitindo que se façam chamadas ou envios de mensagens de texto SMS através da tela e/ou controles do navegador. Dessa forma, o equipamento se torna uma central de informação e comunicação, fazendo com que o motorista não precise nem procurar nem operar seu telefone no momento da condução do veículo.

Muitas outras possibilidades de uso desses equipamentos vêm surgindo no campo da comunicação sem fio. Em serviços como centrais de táxi, é possível fazer a localização mais rápida e eficiente dos táxis nas vias quando estes são solicitados pelos clientes. Com todas essas possibilidades apresentadas acima, e mais outras que podem surgir com as tecnologias já existentes, é provável que esses equipamentos se tornem, num futuro próximo, um dos principais relacionados à mobilidade humana.

Hoje em dia, o grande boom em sistemas de navegação GPS têm sido os aplicativos para smartphones (como o Apple iPhone) criados pelos principais desenvolvedores desses sistemas, como a Garmin, a TomTom e a Nav n Go. Essas empresas desenvolveram versões simplificadas de seus softwares para uso nesses telefones celulares, que se conectam aos satélites GPS através do sistema A-GPS (GPS assistido). Esse sistema utiliza, basicamente, o suporte das conexões de dados dos celulares, como a GPRS e a 3G, para calcular as coordenadas de posição do aparelho com mais eficiência.

\section{A usabilidade}

A usabilidade é definida pela ISO 9241-11 (INTERNATIONAL..., 1998) como a "medida na qual um produto pode ser usado por usuários específicos para alcançar objetivos específicos com eficácia, eficiência e satisfação em um contexto específico de uso". Sendo:

- Eficácia - A acurácia e completude com as quais usuários alcançam objetivos específicos, ou seja, o grau com que uma tarefa é realizada, se é possível completá-la ou não;

- Eficiência - Os recursos gastos em relação à acurácia e abrangência com as quais usuários atingem objetivos, isto é, o nível de esforço despendido pelo usuário para concluir uma tarefa;
- Satisfação - A ausência do desconforto e presença de atitudes positivas em relação ao uso de um produto.

Para tentar satisfazer esses três requisitos no projeto de um determinado produto, seja ele um hardware ou um software ou a união dos dois um produto eletrônico, alguns pesquisadores criaram diversos princípios, critérios e heurísticas de usabilidade, como Bastien e Scapin (1993), Nielsen (1994), Shneiderman (1998), Jordan (1998) e Norman (2002).

0 objetivo maior de todos esses princípios é facilitar a interação do usuário com o produto. Brangier e Barcenilla (2003) classificam esses princípios em quatro categorias de acordo com seus objetivos específicos:

- Facilitar o aprendizado do sistema - Princípios que lidam com questões relacionadas ao primeiro uso de um sistema, no momento em que o usuário faz deduções de como interagir, visando ajudar o usuário novato a começar a interação com o sistema. Essa categoria engloba o princípio de compatibilidade entre produtos e situações, e a transparência das funcionalidades e procedimentos do sistema/produto;

- Facilitar a procura, a percepção, o reconhecimento e a compreensão das informaçóes no sistema - Princípios relacionados à apresentação das informações no sistema. Essa categoria engloba os princípios de agrupamento, clareza visual, legibilidade, carga cognitiva do usuário, memorização, consistência e padronização das informações;

- Facilitar o controle da interação com o sistema Princípios que tratam de questões relacionadas ao desenrolar das atividades, sejam questões normais da interação do usuário com o sistema ou situações de incidência de erros. Os princípios dessa categoria são o feedback, o controle do usuário e o gerenciamento de erros (prevenção, ajuda e recuperação de erros);

- Considerar o contexto de uso do sistema e o tipo de usuário - Princípios relacionados às questões de uso avançado do sistema, como a adaptabilidade e a flexibilidade que o sistema fornece ao usuário.

\section{A interação usuário-sistema GPS}

Basicamente, existem dois momentos no uso de um sistema de navegação. No primeiro, o usuário interage com o sistema para inserir os dados do destino, onde ele determina como o sistema deve calcular a sua rota, seja por um endereço específico, por um cruzamento ou por um ponto de interesse. É nessa interação que ocorre a maior parte dos problemas relacionados à navegabilidade da interface, à compreensibilidade e à consistência das informações, pois existem muitos dados distribuídos 
em vários níveis na hierarquia do sistema, em uma tela razoavelmente pequena. Em média, o tamanho das telas de um navegador é de 4 polegadas.

Já no segundo momento, o usuário interage com o sistema através do chamado "guia de rota”, que é o conjunto de mensagens de voz e informações gráficas (mapas, setas, tempo, quilometragem etc.) apresentado pelo sistema para que o motorista siga até o destino. Nessa interação, a maioria dos problemas está relacionada à precisão das informações, ao tempo de resposta do sistema e à leiturabilidade e poluição visual das informações apresentadas na tela.

Nowakowski, Green e Tsimhoni (2003) apontam que, apesar de os sistemas de navegação já existirem há muito tempo e mesmo que diversas guidelines (ALLIANCE..., 2003; SOCIETY..., 2004; JAPAN..., 2000) já tenham sido publicadas, os problemas de usabilidade desses sistemas ainda continuam ocorrendo. Os autores fizeram várias avaliações do uso de alguns sistemas por usuários, levantando uma série de problemas de usabilidade, relativos tanto à entrada de dados do destino quanto ao uso do guia de rota. Noel, Nonnecke e Trick (2005a,b) também realizaram seus estudos com navegadores e levantaram problemas de usabilidade muito semelhantes, principalmente no que se refere ao aprendizado e memorização do sistema. Esses problemas são apresentados a seguir.

Em relação à entrada de dados do destino, os principais problemas encontrados foram:

- Controles e menus com abreviações ou termos vagos (ex. POI - point of interest - ponto de interesse);

- Agrupamento inconsistente dos comandos nas telas, desconsiderando conceito de agrupamento lógico de subgrupos;

- Controles críticos, para o uso com o veículo em movimento, fora do alcance do motorista;

- Organização e hierarquia confusa dos menus e comandos - usuários não sabiam onde achar determinadas funções;

- Quanto ao feedback sonoro, muitos equipamentos só emitiam um único tipo de som, causando confusão aos usuários quanto à compreensão da resposta do sistema;

- Muitos erros relacionados à ordem de entrada dos dados do endereço - a maioria dos usuários iniciou a entrada dos dados com o nome da via ao invés de iniciar com a seleção da cidade em primeiro lugar, como é requisitado pelos sistemas;

- Usuários ficaram perdidos na navegação da entrada dos dados - os sistemas não apresentaram as informações já inseridas anteriormente pelos usuários nas telas posteriores;

- Usuários apontaram que existiam muito passos a serem percorridos para inserir os dados e que isso era cansativo;
- Por algum erro do usuário, os sistemas perdiam dados do endereço já inseridos, fazendo com a mesma tarefa fosse realizada múltiplas vezes;

- Usuários ficaram confusos em relação à nomenclatura do tipo de via (rua, avenida, alameda etc.), muitos não sabiam se era necessário inserir essas palavras antes do nome da via. Em alguns sistemas o nome do tipo de via era abreviado.

Já em relação ao guia de rota, os problemas mais apontados foram:

- A apresentação da rota de maneira confusa e em alguns casos nem foi apresentada. Confusão devido ao zoom e vias da rota sem identificação;

- 0 alerta do sistema de que o motorista tinha chegado ao destino antes mesmo de chegar - às vezes em uma via paralela ou numa esquina;

- Ao chegar no destino o motorista não sabia se o número da edificação era do lado direito ou esquerdo da via;

- Os textos e símbolos dos sistemas eram muito pequenos - problemas de legibilidade;

- Em áreas urbanas, os mapas ficavam com muitas informações (como os ícones dos POls) enchendo muito os mapas e causando poluição visual. No modo noite (tela com cores mais escuras) a impressão foi de mapas mais cheios, mais confusos. $\mathrm{Na}$ visão 3D, os mapas também se tornavam bem poluídos;

- Algumas vias importantes não foram identificadas no mapa, como a via em que se estava entrando;

- Quando a via para entrar não estava claramente visível, muitos motoristas ficaram com os olhos fixados na barra de contagem regressiva, ao invés de focarem na via;

- Uso de terminologias vagas (como, "numa curta distância" e "adiante") levou a várias manobras erradas e situações de pânico. Os motoristas interpretam, em geral, mensagens ambíguas como "vire imediatamente";

- Uso de termos incorretos para descrever a geometria da via, como "agulha" ou "rótula". Nessas situações os motoristas costumam ficar agitados, confusos e irritados com o navegador;

- Como as mensagens de manobra indicavam a distância em metros remanescentes, como "vire à direita daqui a 300 metros", muitos motoristas ficaram confusos e aflitos por não saberem estimar em tempo essas distâncias;

- Demora dos sistemas para recalcular a rota, fazendo com que o motorista ficasse sem saber que atitude tomar;

- Alguns navegadores calcularam rotas longas quando os próprios motoristas perceberam que a rota poderia ter sido mais curta;

- Os navegadores no momento em que estavam recalculando a rota emitiam uma série de avisos, fazendo com que o motorista ficasse confuso e irritado por não entender as instruções. 
Boa parte dos problemas de usabilidade dos sistemas de navegação GPS está relacionada ao tamanho pequeno da tela, onde são apresentadas as informações. Esses problemas ocorrem, em geral, devido à quantidade de informações que devem ser lidas na tela, ao modo de inserção de dados nos sistemas, em várias etapas, e a quantidade de funcionalidades que devem ser acomodadas em diversos menus na interface.

Esse tipo de tecnologia é muito recente no Brasile o mercado ainda está se adaptando, comercializando produtos estrangeiros com traduções do conteúdo dos sistemas vendidos em outros países. Como as culturas são diferentes, acredita-se que se deve haver uma adaptação desses sistemas ao público brasileiro e que testes de usabilidade devem ser aplicados com esse público, apesar da globalização dos sistemas computacionais.

\section{Métodos, técnicas e procedimentos}

Com o objetivo de investigar se problemas de usabilidade relacionados à entrada de dados do destino também ocorrem em sistemas de navegação GPS vendidos no Brasil, foram aplicados testes de usabilidade em três sistemas com ampla difusão no mercado brasileiro e com projetos de interface bastante diferenciados. 0 intuito do teste foi verificar a conformidade das interfaces com os princípios de usabilidade apresentados anteriormente. De acordo com Dumas e Loring (2008, p. 2), o teste de usabilidade

[...] é uma forma sistemática de observar os usuários de um produto trabalhando com ele sob condições controladas. Ele difere de outros métodos de avaliação (tais como teste de qualidade ou demonstrações do produto) em que os usuários tentam completar tarefas por conta própria, com pouca ajuda.

Sendo assim, o projeto e a estrutura do teste de usabilidade desta pesquisa foram organizados de acordo com as etapas de planejamento definidas por Rubin e Chisnell (2008) - pesquisadores renomados da área de ergonomia e interação humano-computador.

\subsection{Participantes}

Participaram dos testes 18 motoristas habilitados, sendo 9 experientes com sistemas de navegação GPS e 9 não experientes. Doze do sexo masculino e 6 do sexo feminino. As idades dos participantes variaram da faixa etária de 21 a 30 anos à faixa de 51 a 60 anos. Mais da metade respondeu que dirigia em média mais de quatro horas por semana, enquanto os outros participantes estiveram equilibrados entre as conduções de até uma hora semanal a até 4 horas semanais.

\subsection{Sistemas avaliados}

Os três sistemas/softwares avaliados foram: sistema A - Nav N Go iG0 8; sistema B - Route 66 Navigate 7; sistema C - TomTom Navigator 7. 0s três softwares foram instalados no mesmo hardware com tela touch-screen - Pocket PC Airis T620 com antena GPS embutida. Optou-se pelo uso do mesmo hardware nos testes para que o foco fosse apenas nos problemas e soluções da interface computadorizada.

Esses três sistemas possuem métodos de entrada de dados de endereço bem diferentes. No primeiro, a entrada de dados é feita por um teclado que reduz as possibilidades de entrada (de teclas) conforme é feita a digitação do nomes das ruas, das cidades e dos números da edificação (Figura 1). No segundo, o usuário digita completamente ou parcialmente o endereço e depois o procura em uma lista de possibilidades, numa tela seguinte (Figura 2). No terceiro, conforme o usuário digita os nomes, o sistema os filtra no banco de dados e apresenta as possibilidades numa lista de duas linhas (Figura 3). Quanto ao menu principal das interfaces, o primeiro tem arranjos de menus (subgrupos) bem diferentes dos outros dois, que são semelhantes em termos de disposição dos comandos/itens de menu na interface (Figura 4).

\subsection{Tarefas e procedimentos}

Para avaliar os diferentes métodos de entrada de dados do destino e a organização/navegação de comandos, solicitou-se que cada um dos participantes definisse um destino por endereço (tarefa 1) e selecionasse como destino o posto de gasolina (POI) mais próximo do sinal GPS - mais perto da localização do veículo (tarefa 2).

As instruções das tarefas foram dadas para os participantes através de cartões, com os cenários demonstrados no Quadro 1.

Os testes foram realizados dentro de um veículo (sempre o mesmo veículo), parado em um estacionamento ao ar livre, durante a manhã e a tarde, para que a incidência de luz pudesse ser semelhante. 0 equipamento GPS, onde foram instalados os sistemas, esteve sempre no mesmo local - preso na parte mais baixa do para-brisas próximo à parte central do painel de instrumentos (Figura 5). Esse local é o recomendado para a realização de tarefas secundárias em veículos com displays, que precisam ser vistos e acionados sem a obstrução da visão com a via e sem interferir nos 

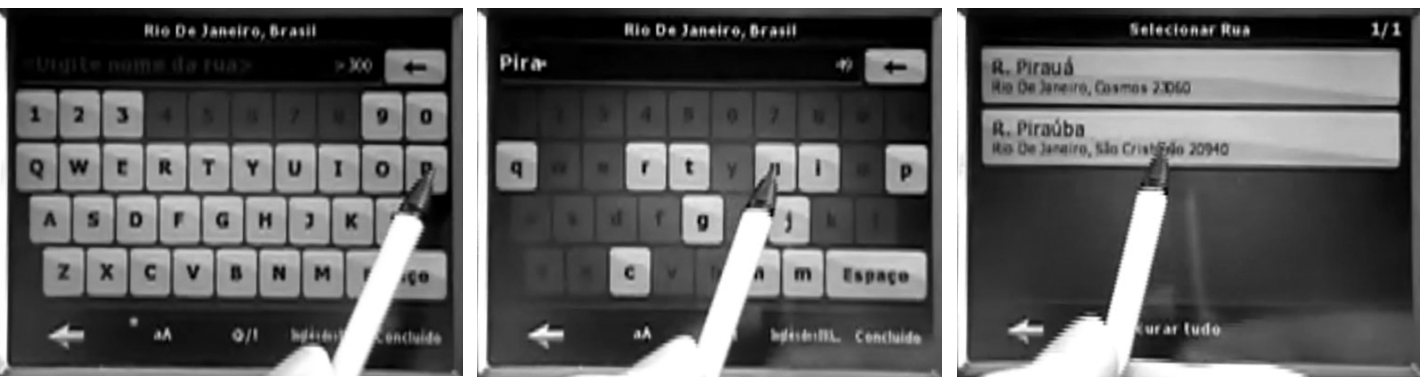

Figura 1. Modo de entrada de dados do sistema A - Nav N Go iGO 8.
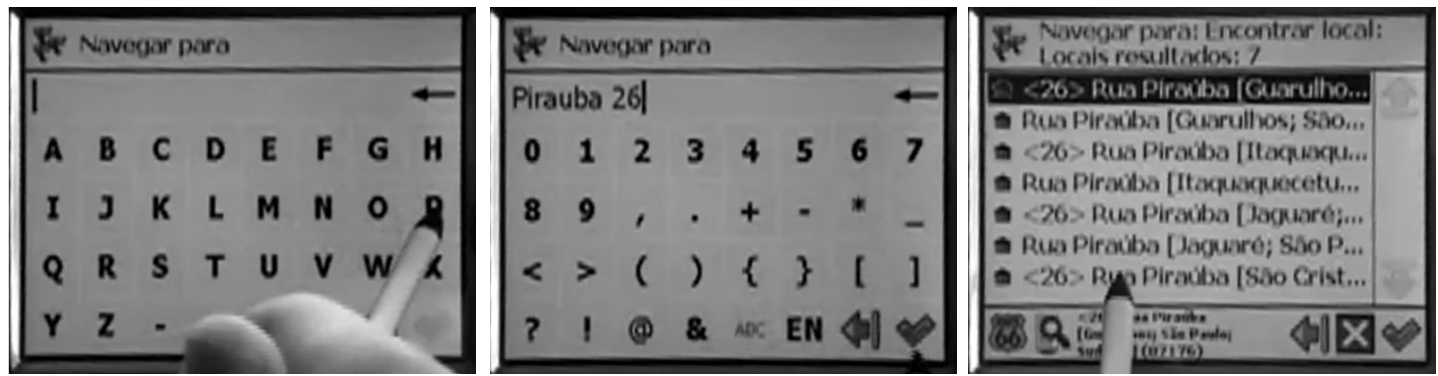

Figura 2. Modo de entrada de dados do sistema B - Route 66 Navigate 7.
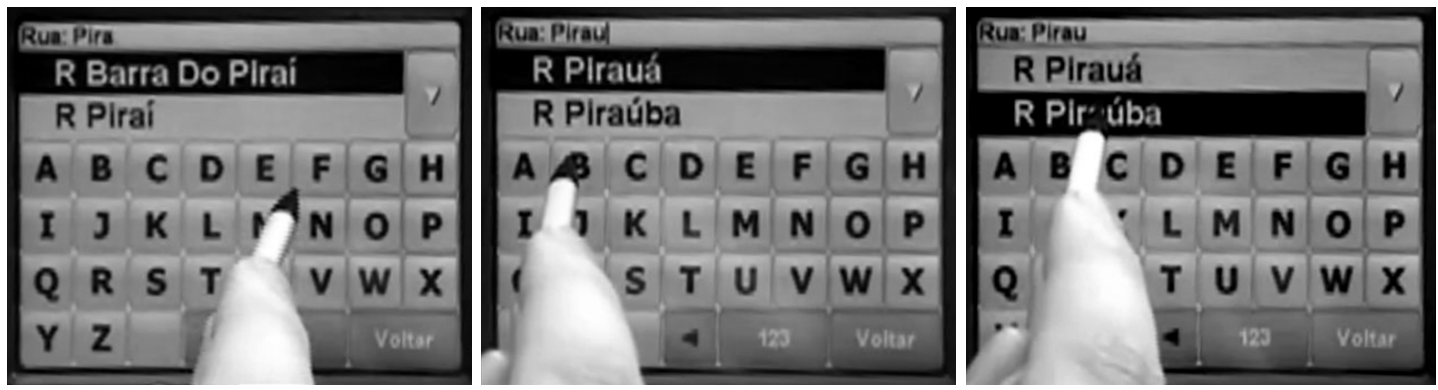

Figura 3. Modo de entrada de dados do sistema C - TomTom Navigator 7.

controles do veículo, conforme as recomendações das diretrizes europeias (EUROPEAN..., 2008) e americanas (ALLIANCE..., 2003). Todas as etapas do teste foram gravadas em vídeo digital através de uma câmera instalada em um tripé no banco de trás do veículo.

Os três sistemas foram avaliados por todos os participantes separadamente, porém a ordem de apresentação dos sistemas foi contrabalançada entre eles, para evitar que os resultados fossem tendenciosos para um ou outro sistema. Também, as tarefas foram entregues de maneira aleatória, sendo que na tarefa 1 foram utilizados três endereços diferentes com o mesmo número de letras e número de edificação, um para cada sistema.

Antes de realizar as tarefas em cada sistema, o participante fazia um ensaio para conhecer o sistema que seria testado. Após o ensaio, o participante recebia os cartões com as tarefas,
Quadro 1. Cenários das tarefas do teste de usabilidade.

\begin{tabular}{|c|l|}
\hline Tarefa 1 & $\begin{array}{l}\text { "Você mandou imprimir uns convites numa } \\
\text { gráfica em São Cristóvão e precisa buscá-los. } \\
\text { Como você não sabe chegar lá, vai utilizar o } \\
\text { seu sistema GPS para guiá-lo. Para isso, você } \\
\text { precisa colocar o endereço (abaixo) no sistema } \\
\text { para que ele calcule a sua rota e o guie. Como } \\
\text { você faria isso? ENDEREÇO" }\end{array}$ \\
\hline Tarefa 2 & $\begin{array}{l}\text { "Você está dirigindo numa região que não } \\
\text { conhece direito e, de repente, verifica que } \\
\text { precisa abastecer o carro. Sabendo que seu } \\
\text { sistema GPS pode informar qual é o posto } \\
\text { de gasolina mais próximo da posição em que } \\
\text { você está e guiá-lo até lá, como você faria para } \\
\text { selecionar como destino o posto de gasolina } \\
\text { mais próximo?” }\end{array}$ \\
\hline
\end{tabular}

uma de cada vez e, então, as executava. Após os testes de todos os sistemas, foram feitos debriefings (entrevistas de revisão) com os participantes, para 


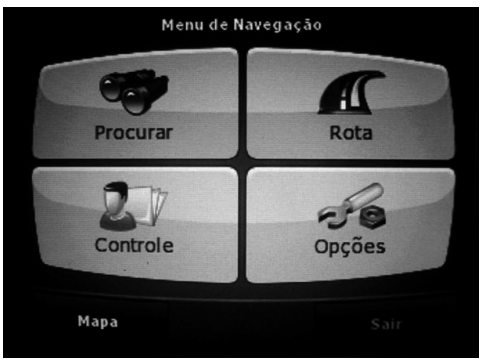

Sistema A

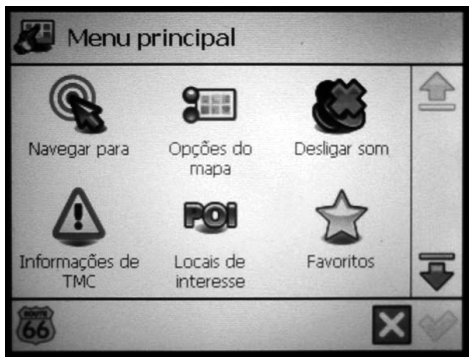

Sistema B

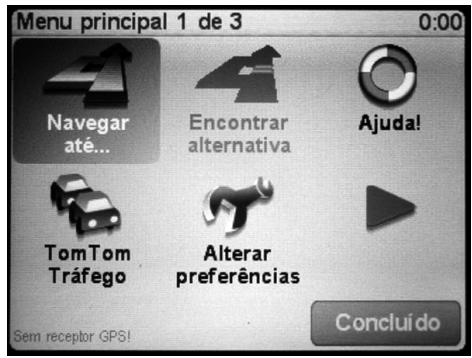

Sistema C

Figura 4. Menu principal dos sistemas testados (sistema A - Nav N iGO 8; sistema B - Route 66 Navigate 7; sistema C TomTom Navigator 7, respectivamente).
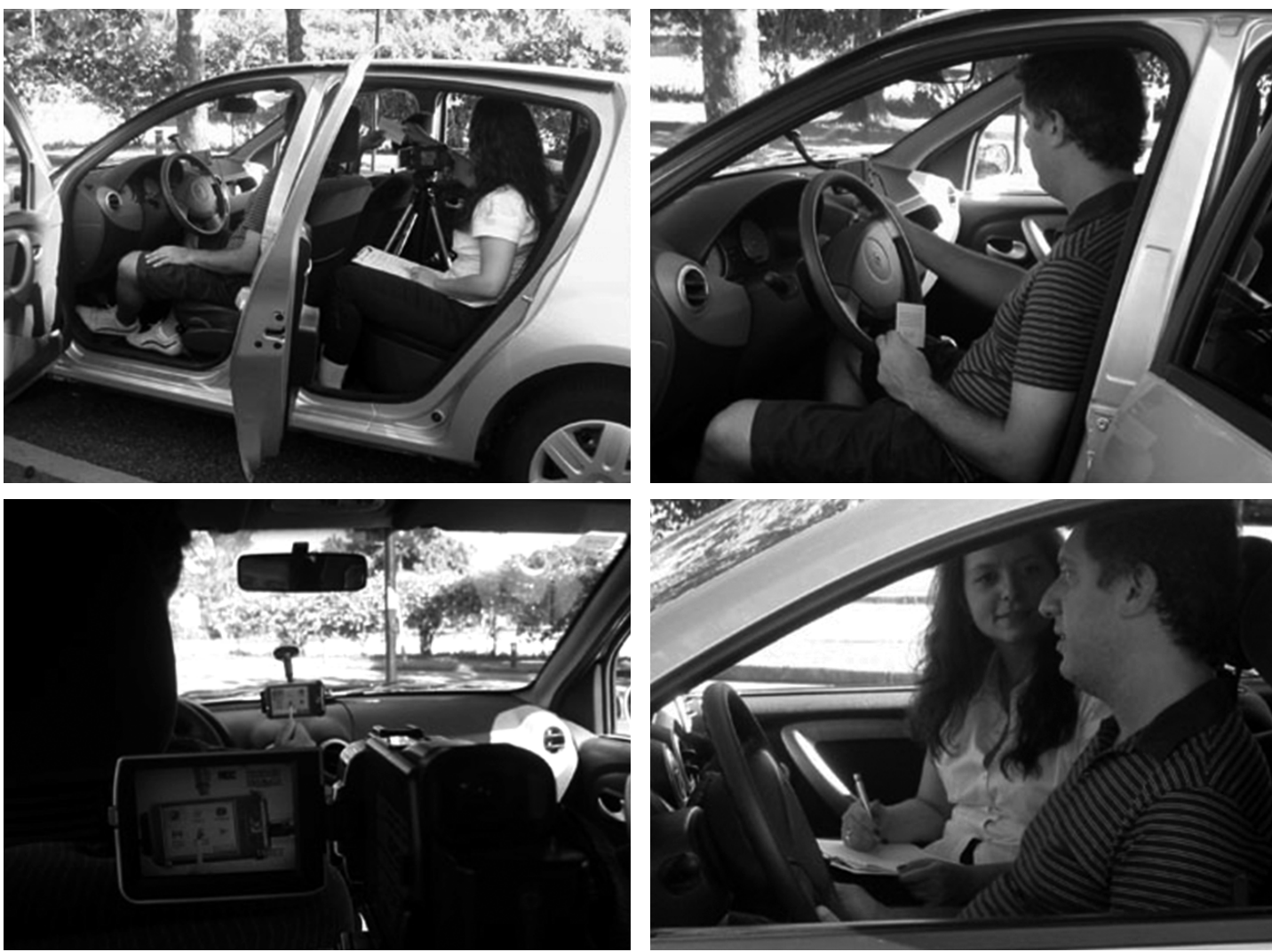

Figura 5. Ambiente e equipamentos dos teste de usabilidade.

esclarecer algumas questões que foram observadas e saber mais sobre sua opinião, sua satisfação e preferências.

\section{Resultados}

\subsection{Completude da tarefa (eficácia)}

Para a medição da completude das tarefas, foram observados e tabulados todos os cliques efetuados durante a execução das tarefas, através das gravações de vídeo dos testes. Para confirmar se a tarefa foi completada, mesmo que os participantes tenham dito que a concluíram, utilizou-se como critério de completude os fluxogramas das atividades das tarefas gerados no plano de teste. Se o participante tivesse passado por todas as atividades da tarefa do início ao fim, esta foi considerada como completada. Porém, se o participante não chegou ao fim, falhando em uma ou várias atividades, esta foi classificada como não completada. Para as que foram finalizadas 
com problemas, foi constatado que o participante passou por todas as atividades do início ao fim, mas que além, das tarefas, ele realizou outras atividades desnecessárias.

A Figura 6 apresenta os níveis de completude da tarefa 1 nos sistemas. É possível observar que o sistema A se mostrou o mais eficaz dos sistemas, com 39\% de completude sem problemas. 0 sistema $C$ também apresentou resultados razoáveis quanto à eficácia, mas o nível de completude sem problemas foi muito baixo (11\%), o que mostra que há problemas quanto à eficiência. Já o sistema $\mathrm{B}$ apresentou resultados insatisfatórios, pois não houve a conclusão da tarefa sem problemas.

0 motivo que levou à incidência de $17 \%$ de não completude da tarefa, no sistema B, foi o fato de alguns participantes não terem inserido o número da edificação do endereço no sistema, para o cálculo da rota para o destino. Normalmente, a inserção de um endereço é feita em etapas, colocando-se primeiro a cidade, depois o nome da rua e no final o número da edificação, em telas diferentes. Nesse sistema, a inserção do endereço é feita de modo diferente, tanto dos outros sistemas testados quanto de outros existentes no mercado. Para a inserção do endereço no sistema B, o usuário insere o endereço completo (com nome da rua, número e cidade) para depois procurá-lo e selecioná-lo numa lista de opções de endereços. Dessa forma, os participantes não souberam como inserir o número ou nem perceberam que não o fizeram, colocando apenas o nome da rua e concluindo que a tarefa estava terminada. lsso mostra um problema de compatibilidade entre sistemas, assim como um problema de feedback, pois o sistema não mostra para onde o usuário está indo, apesar de, na prática, levá-lo ao centro da rua selecionada.

Para escolher um ponto de interesse como destino o usuário seleciona, em geral, um comando inicial "navegar até/para" ou "procurar", depois seleciona o subgrupo de POls, especifica qual referência de proximidade do $\mathrm{POl}$ (ou mais próximo da posição GPS, ou do destino, ou mais perto de um endereço, entre outros), seleciona a categoria de POI específica (como posto de gasolina, restaurante, shopping etc.) e, no final, determina o POI específico para onde pretende ir. Esse processo é bem semelhante entre os três sistemas, mas com algumas variações.

$\mathrm{Na}$ Figura 7 apresentam-se os níveis de completude da tarefa 2 nos três sistemas. Pode-se observar que os dois primeiros sistemas ( $\mathrm{A}$ e B) foram os que tiveram mais problemas quanto à eficácia, enquanto o sistema $C$ teve uma incidência muito baixa.
No sistema A, ocorreu um problema relacionado à percepção e reconhecimento da informação, devido ao formato do comando para a seleção do POl específico (o posto de gasolina mais próximo) e seu rótulo. Como pode ser visto nas figuras seguintes, a seleção do posto de gasolina nesse sistema pode ser feita tanto por bandeira de posto, selecionando-se o botão da bandeira desejada (Figura 8), quanto por qualquer posto independente da bandeira, selecionando-se o botão "Tudo na categoria atual" (Figura 9). Na tarefa solicitada, o participante deveria escolher o posto de gasolina mais próximo da posição em que ele se encontrava independente da bandeira, e para tanto ele deveria selecionar o comando "Tudo na categoria atual" (Figura 9). Porém, como esse comando tem um destaque e icone diferentes dos da bandeira, alguns participantes ignoraram o comando, considerando que ele seria um título da tela, não o selecionando e optando por uma bandeira de posto. Outros chegaram a questionar por que não havia uma opção "Todos" ao invés de mostrar por bandeira. Isso deixa claro que o rótulo

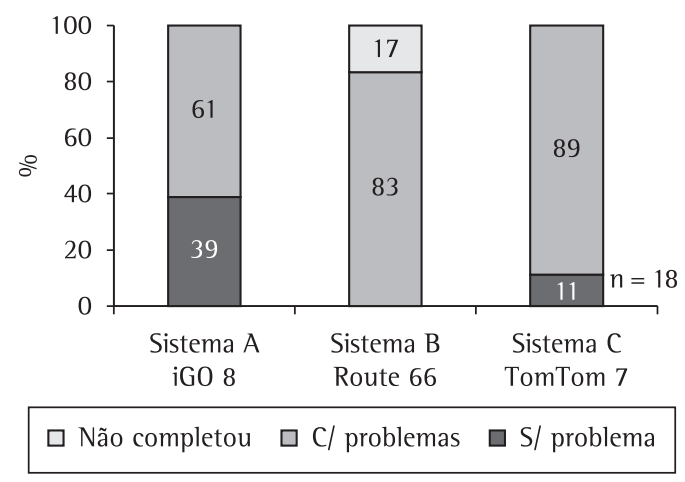

Figura 6. Níveis de completude da tarefa 1 - definir o destino por endereço.

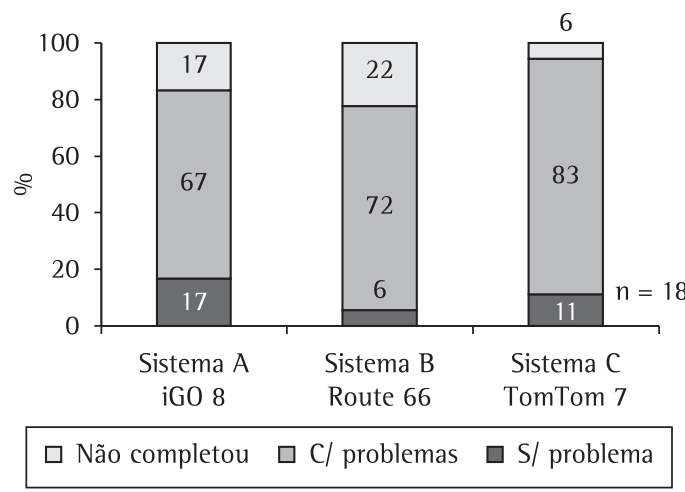

Figura 7. Níveis de completude da tarefa 2 - selecionar como destino o posto de gasolina (POI) mais próximo do sinal GPS. 
“Tudo na categoria atual” não é o mais adequado para o comando, onde a palavra "Todos" talvez pudesse ter um significado melhor, conforme o comentário de um dos participantes: "Ele não tem a opção “Todos'?”.

No sistema B, o motivo que levou à não completude da tarefa 2 foi a seleção errada da referência de proximidade de POI. Nesse sistema só existem duas referências de proximidade: "POI perto da posição GPS" e "POl perto do destino". Acredita-se que os participantes selecionaram a referência errada (POI perto do destino) devido à legibilidade e clareza visual de seu rótulo, pois, além de as letras serem finas e pequenas, o texto está compactado para ficar ajustado abaixo do ícone, apesar de os outros dois sistemas terem rótulos semelhantes na extensão dos textos.

\subsection{Eficiência da tarefa}

Para avaliar quão custosa a tarefa pode ser para o usuário, ou seja, o quão eficiente é a tarefa, foram contados os números de cliques (seleção de comandos/itens ou teclas) que cada participante executou, em cada tarefa e em cada sistema. Paralelamente, foram contados os cliques mínimos que seriam necessários para a conclusão da tarefa. Comparando esses dois valores, foi possível mensurar a média do nível de esforço que os participantes tiveram para concluir as tarefas. Nessa medição só foram contabilizadas, portanto, as tarefas que foram concluídas - sem e com problemas.

Com essas comparações entre cliques mínimos e cliques executados, pôde-se observar duas questões: $1^{\text {a) }}$ somente pelos cliques mínimos, qual dos três sistemas tem a solução de execução da
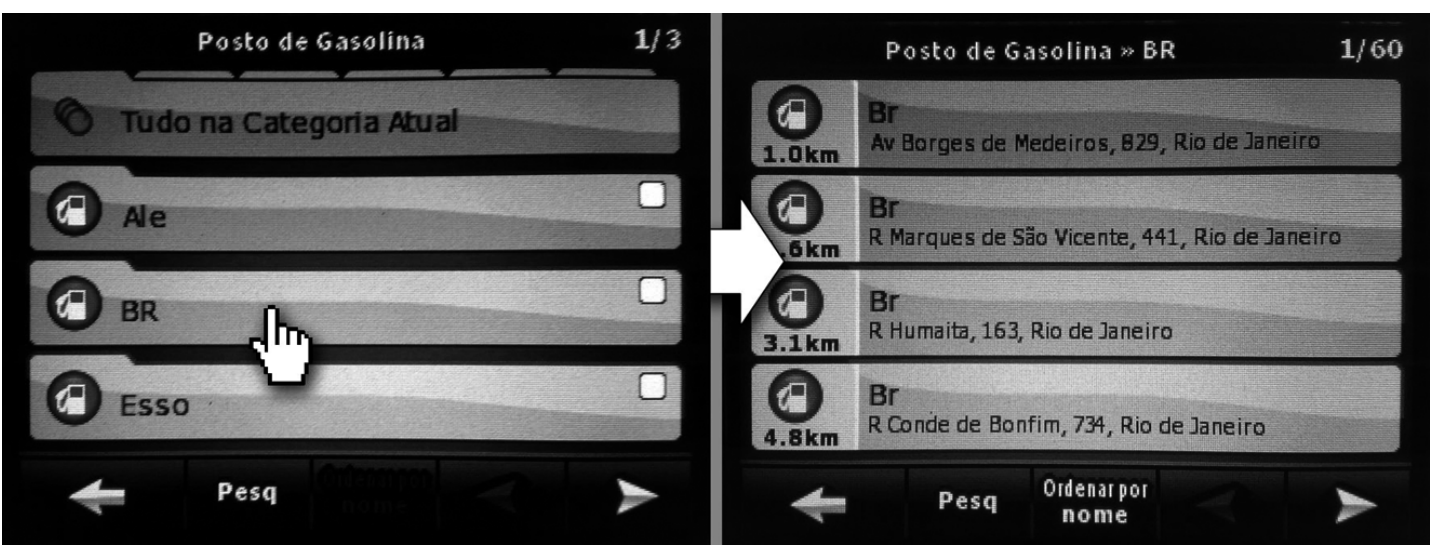

Figura 8. Sistema A - seleção de posto de gasolina por bandeira (exemplo da sequência de telas na seleção do botão da bandeira BR).

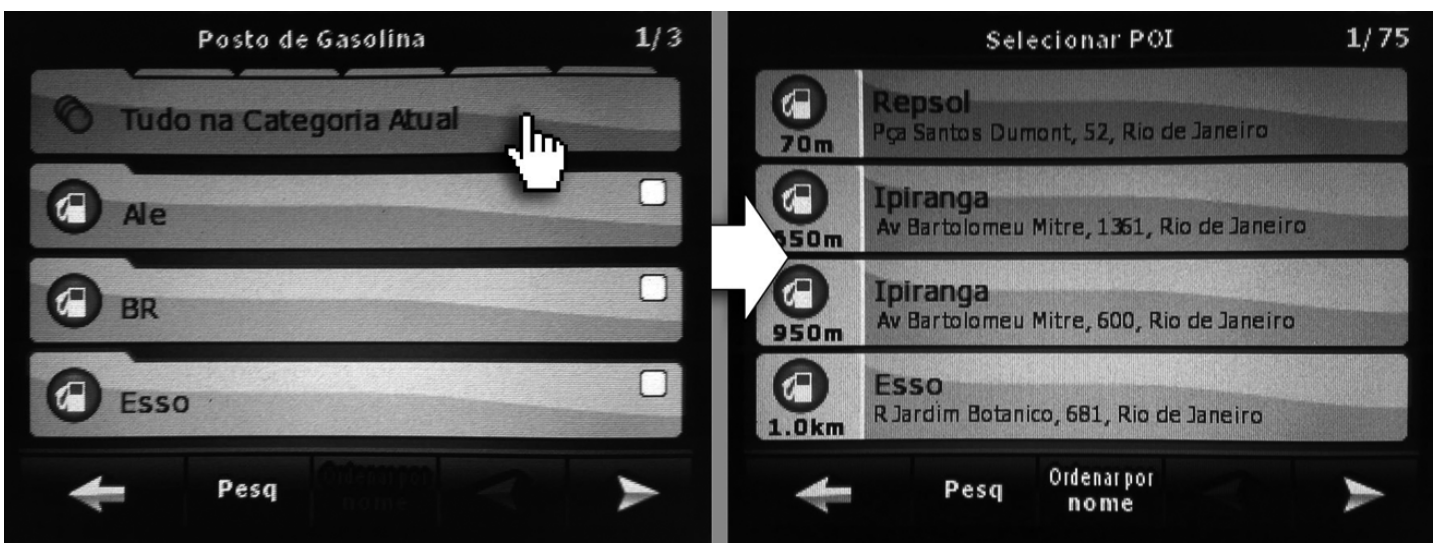

Figura 9. Sistema A - seleção de posto de gasolina independente da bandeira (exemplo da sequência de telas na seleção do botão “Tudo na categoria atual”). 
tarefa mais eficiente, ou seja, a que tiver menor número de cliques é, teoricamente, a mais rápida e mais eficiente; e $2^{\text {a }}$ com os valores de cliques executados, qual tarefa apresentou o maior ou menor custo para ser concluída.

$\mathrm{Na}$ tarefa 1 - definir um destino por endereço, observa-se na Figura 10 que os sistemas A e C possuem a quantidade menor de cliques mínimos (14 cliques) para a sua conclusão. lsso significa que as soluções para a execução da tarefa nesses sistemas, em princípio, são mais eficientes do que no sistema B. Ao observar a média de cliques excedentes e/ou errados realizados pelos participantes na Figura 11, pode-se dizer que o projeto do sistema A é o mais eficiente dentre os três sistemas, com média de 70\% de cliques a mais que o necessário para completar a tarefa. Para a obtenção deste resultado, apresentado na Figura 11, foi computada a quantidade de cliques excedentes/errados realizados pelos participantes que concluíram a tarefa com problemas. Sendo assim, dos 61\% dos participantes que concluíram a tarefa com problemas no sistema A, estes realizaram em média $70 \%$ de cliques a mais que o necessário. No sistema B, 83\% dos participantes clicaram em média 165\% de cliques a mais, e no sistema C, $89 \%$ dos participantes excederam a quantidade de cliques em 121\%. Dessa forma, concluiu-se que o sistema A é o mais eficiente, ainda mais se for considerado o seu nível de completude sem problemas (39\%), comparado com o mesmo nível dos outros dos sistemas.

Apesar de o sistema A, nessa tarefa, ter se apresentado como o mais eficiente, nele também ocorreram problemas de usabilidade. Os principais foram relacionados à compatibilidade do sistema com outros sistemas, com o modo de pensar do usuário e à condução do sistema para a inserção dos dados.

No sistema B, que apresentou a maior quantidade de problemas, um dos motivos que levou ao excesso de cliques foi o mesmo problema que ocorreu com a não completude da tarefa, onde muitos participantes não inseriram o número da edificação junto com o nome da via. Portanto, os participantes que perceberam esse problema de compatibilidade do sistema refizeram a tarefa e, consequentemente, excederam o número de cliques mínimos necessários.

Já no sistema $\mathrm{C}$, um dos motivos que levou ao excesso de cliques foi uma falta de informação/ confirmação, pois em nenhum momento o sistema apresenta para o usuário o bairro onde está localizado o endereço. Apesar de não ser uma informação solicitada no processo de entrada de dados, os outros dois sistemas (A e B) apresentam o bairro no momento de seleção do endereço. De acordo com o que foi discutido com alguns participantes, esse feedback é importante porque, numa mesma cidade, podem existir ruas com o mesmo nome ou partes de nomes iguais. Para alguns participantes isso foi visto como um problema, pois não confiaram no sistema de que a rua que eles selecionaram era a desejada e, portanto, refizeram a tarefa inserindo o CEP para ter certeza de que a rua seria a correta.

Na tarefa 2 - selecionar como destino o posto de gasolina mais próximo do sinal GPS, ao observar gráfico de cliques mínimos necessários (Figura 12), pode-se concluir que o sistema $C$ apresenta um projeto de execução da tarefa mais rápido, com 7 cliques mínimos para completar. Porém, ao verificar na Figura 13, chega-se à conclusão que

Tarefa 1 - eficiência

Número de cliques mínimos necessários para completar a tarefa

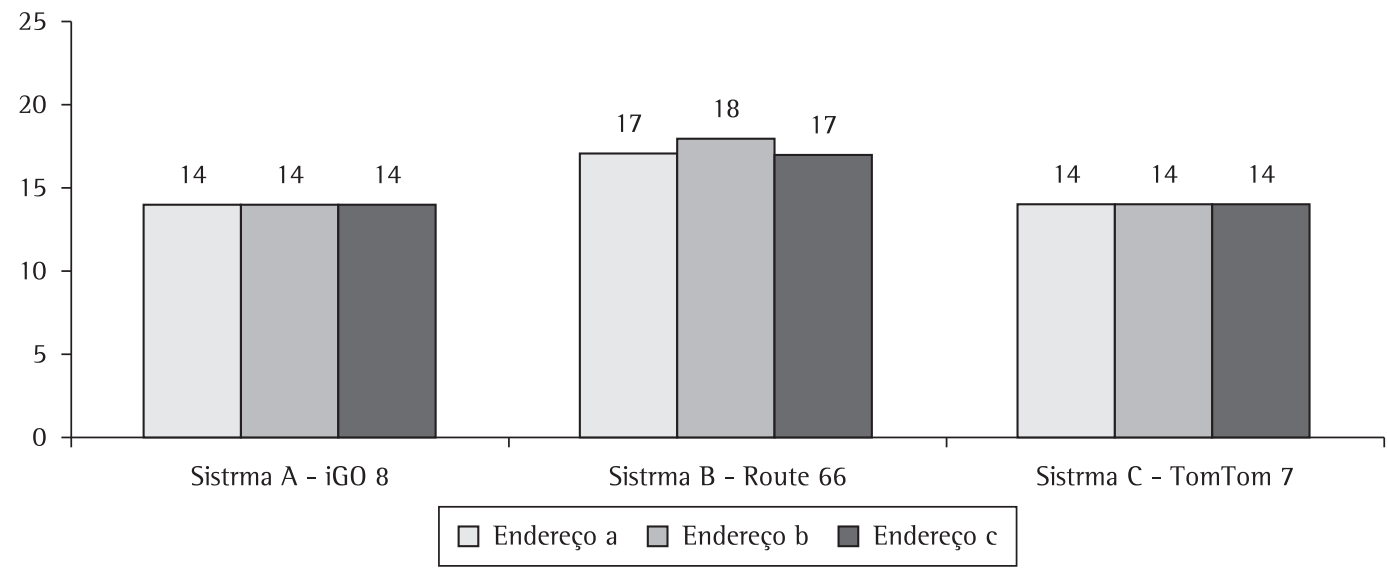

Figura 10. Número de cliques mínimos necessários para completar a tarefa 1 - definir um destino por endereço. 
o sistema A apresenta melhores resultados quanto à eficiência, pois $67 \%$ dos participantes que completaram a tarefa com problemas excederam em cliques 65\% a mais que o necessário e, também, esse sistema teve mais pessoas completando a tarefa sem problemas (17\%).

No sistema B, o principal problema que levou ao excesso de cliques desnecessários foi a longa lista de categorias de pontos de interesse contida nesse sistema. As categorias são apresentadas em 12 telas em ordem alfabética, sendo que a categoria de posto de gasolina fica na $9^{a}$ tela, o que fez com que os participantes clicassem freneticamente nas setas da barra de rolagem para buscar a categoria desejada mais rápido, excedendo assim a quantidade de clique mínimos necessários. Nos outros dois sistemas ( $\mathrm{A}$ e C), a exposição das categorias é feita de maneira mais eficiente. No sistema $A$, existe um número menor, ou seja, um agrupamento melhor de categorias, enquanto no sistema C, são priorizadas, isto é, as mais utilizadas são apresentadas na primeira tela.

No sistema C, o grande problema que ocorreu com o excesso de cliques não esteve diretamente relacionado à tarefa específica, e sim com a quantidade de opções oferecidas em três telas de menu principal. Como nesse sistema existem essas três telas de menu principal, metade dos participantes acabou percorrendo todas as telas antes de selecionar o comando correto e continuar a tarefa. 0 fato de existir mais de uma tela de menu principal distrai o usuário quanto à seleção do primeiro comando da tarefa.

\subsection{Satisfação do usuário}

Uma das questões mais comentadas pelos participantes nos debriefings foi o longo processo necessário para entrada dos dados do endereço. Em geral, é preciso inserir em um sistema GPS os três principais itens de um endereço - o nome cidade, o nome da via e o número da edificação, geralmente, em telas separadas. Muitos participantes questionaram a necessidade de inserir o nome da cidade, uma vez que o sinal do GPS já reconhece a cidade onde o usuário se encontra. Nesse caso, boa parte dos participantes preferiu o modo de entrada de dados do sistema A, que possui uma tela onde são inseridos em etapas os dados do endereço, e nessa tela é possível deixar como padrão o nome da cidade, assim como o nome do país. Isso agiliza o processo, porque dessa maneira só é preciso entrar com o nome da rua e o número.

Apesar de criticarem o longo processo, foi praticamente unânime a preferência pela inserção

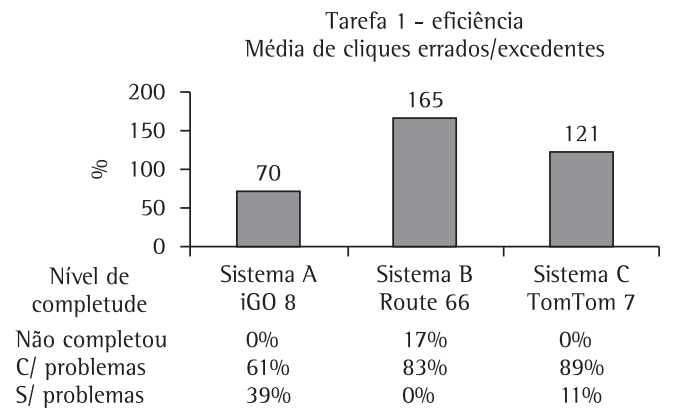

Figura 11. Média de cliques errados/excedentes realizados pelos participantes na tarefa 1 .

Tarefa 2 - eficiência

Número de cliques mínimos necessários para completar a tarefa

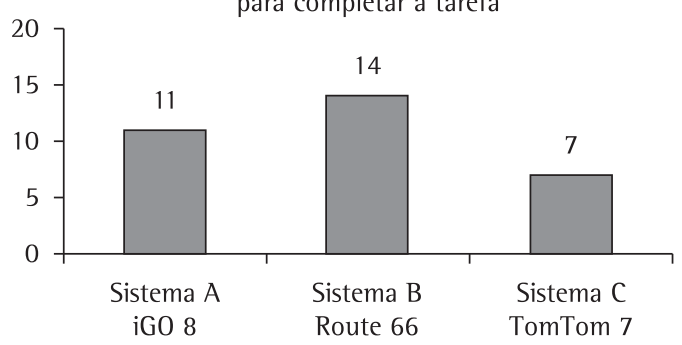

Figura 12. Número de cliques mínimos necessários para completar a tarefa 2 - selecionar como destino o posto de gasolina (POI) mais próximo do sinal GPS.

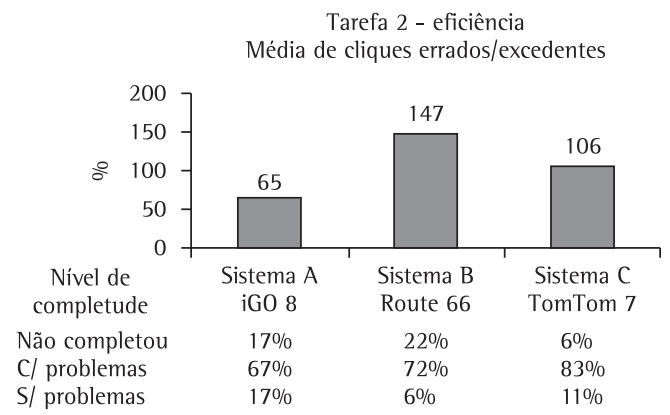

Figura 13. Média de cliques errados/excedentes realizados pelos participantes na tarefa 2 .

dos dados em telas separadas, como é nos sistemas A e C. 0 sistema B foi muito criticado pelo fato de se ter que inserir o número da edificação junto com o nome da rua e depois selecionar o endereço numa lista extensa de todo o Brasil, por não existir um filtro por cidade.

0 modo de digitação do nome da rua no sistema A foi visto, também, como um item positivo do sistema. 0 fato de as letras do teclado irem se apagando, conforme é digitado o nome da rua, foi muito comentado, porque dessa maneira conduz melhor a digitação de letras muito pequenas. Um dos participantes inclusive atentou para o fato de quando 


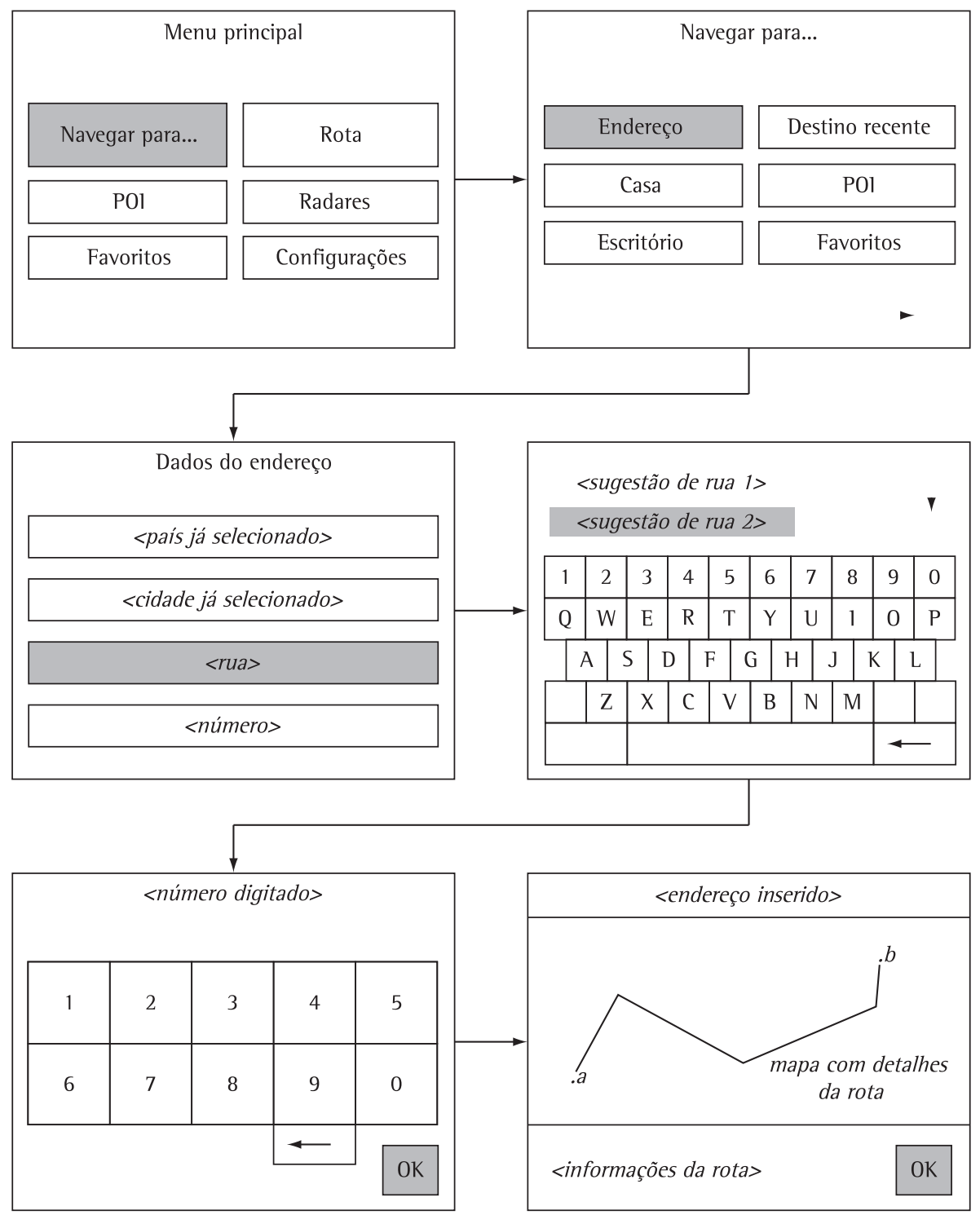

Figura 14. Sequência de telas recomendada para definir um destino por endereço. Os retângulos com preenchimento em cinza indicam o único ou o último comando clicado na tela.

o veículo está em movimento uma tecla errada pode ser digitada devido à sua trepidação. Entretanto, alguns participantes duvidaram da eficiência desse tipo de entrada, pois se uma pessoa tenta entrar com um endereço com a rua digitada errada (com uma das letras errada), o sistema bloqueia o processo de inserção. Neste caso, preferiram o sistema C, que vai dando opções de ruas conforme o nome é inserido, mesmo que a palavra contenha uma das letras errada. Por exemplo, quando se tenta entrar com a rua "Paissandu", escrevendo-se com um "s" só ou "ç", no sistema C, chegará um momento que o sistema apresentará a rua correta ("Paissandu") e, então, o usuário poderá selecioná-la. No sistema A isso não será possível, porque ele não reconhecerá tal nome no banco de dados.

Outra questão bastante discutida foi o formato do teclado. 0 sistema $A$ apresenta o teclado no formato QWERTY, enquanto que os outros dois sistemas apresentam em ordem alfabética (ABCDE). Um pouco mais da metade dos participantes preferiu o teclado no formato QWERTY, mas houve outros participantes que disseram que o ABCDE é melhor, comparando com o teclado de um telefone celular, e outros responderam que eram indiferentes. Sendo assim, acredita-se que esse tipo de sistema deva ter 


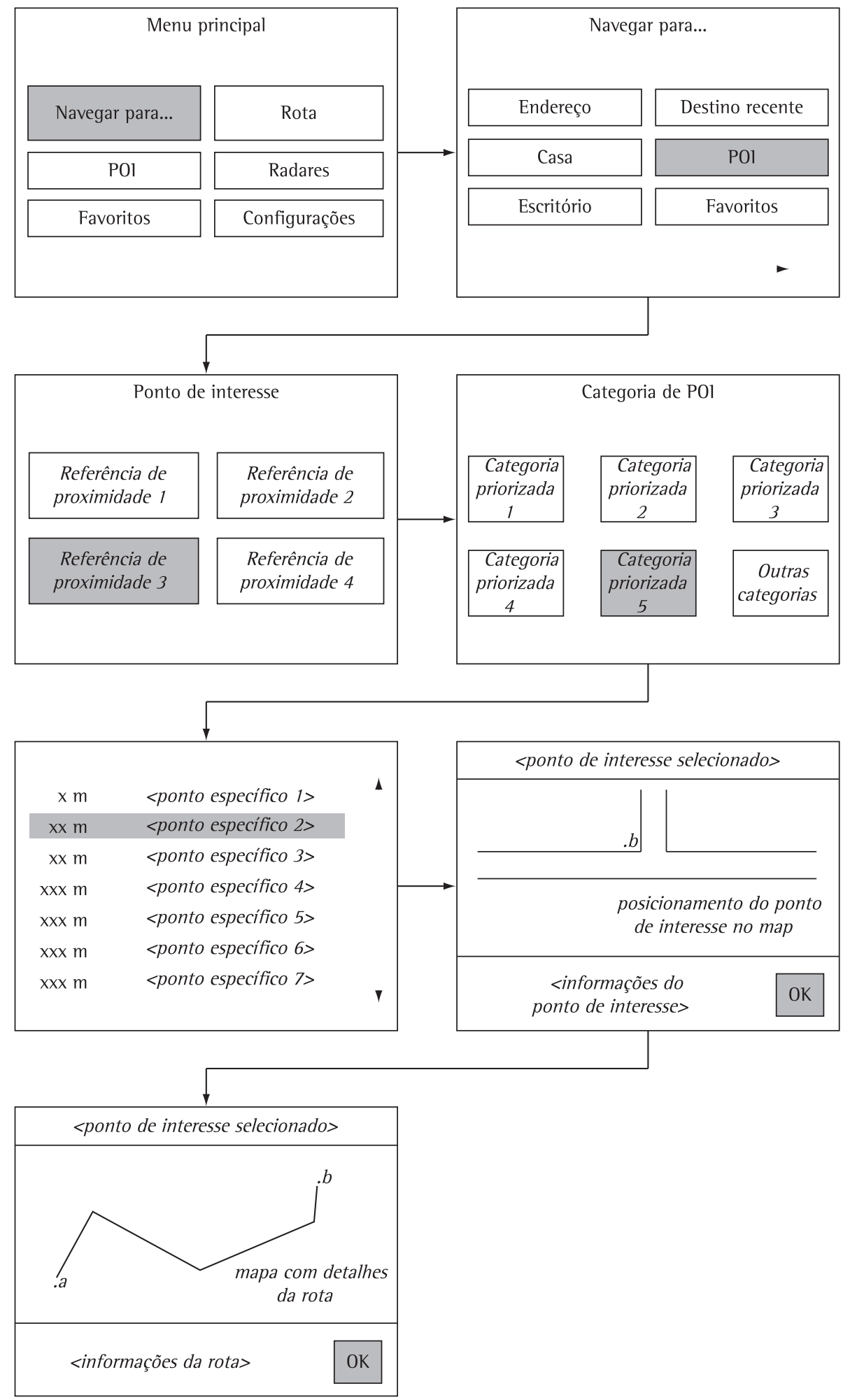

Figura 15. Sequência de telas recomendada para selecionar com destino um ponto de interesse (POI). Os retângulos com preenchimento em cinza indicam o único ou o último comando clicado na tela. 
a opção de escolha de formato de teclados, o que acontece no sistema C. Esse sistema possui esse tipo de configuração, mas como isso não fazia parte de nenhuma das tarefas do teste, os participantes não perceberam.

Em relação à organização dos menus e comandos dos três navegadores, o que foi mais discutido foi o excesso de páginas de menu nos sistemas B e, principalmente, no sistema C. Este último apresenta três telas de menu principal e seis telas de preferências, com 30 comandos em um mesmo nível hierárquico. 0 sistema $A$ foi visto como o melhor em termos de organização, com uma tela de menu principal e quatro grupos de menu básicos apresentados nesta tela. Alguns participantes chegaram a achar que o sistema C, por ter tantas opções em cada nível, tinha mais funcionalidades do que os outros dois, mas de fato ele é equivalente ao sistema A. Quanto ao sistema B, realmente ele possui menos funcionalidades.

Porém, o sistema A teve uma crítica em relação a sua navegação na tela. Foi mencionada por vários participantes a falta de um atalho rápido à tela do menu principal. Quando os participantes chegavam em um nível profundo na hierarquia do sistema, tinham que clicar na seta de voltar diversas vezes para retornar ao menu principal e conseguir chegar no mapa do guia de rota.

Os participantes comentaram, também, sobre a priorização dos comandos dentro dos menus. Apesar de o sistema C ter recebido muitas críticas sobre seu excesso de opções em um mesmo menu, muitos consideraram que as primeiras opções apresentadas são as mais importantes, ou seja, eles acreditam que o sistema até prioriza bem seus comandos, mas acham que eles deveriam ser mais agrupados para melhor navegação. Quanto ao sistema B, foi dito que sua priorização é terrivel, principalmente no caso mencionado antes sobre o excesso de categorias de POls. No sistema A, como seu sistema de organização foi muito bem-visto, os participantes mencionaram que a priorização dos comandos é, também, muito boa.

Muitos participantes sugeriram que o menu principal (primeira tela) deva ter no máximo quatro ou cinco opções e que tudo que o navegador contém deva ser acessado por ali. Além disso, acreditam que o comando "Navegar até" deva ser o primeiro comando apresentado em um sistema desses, já que aponta para a tarefa principal do sistema.

Por último, em relação à organização dos comandos de pontos de interesse, definitivamente o sistema B foi o mais criticado, devido aos seus comandos espalhados em níveis diferentes e, mais ainda, devido à longa lista de categorias de POI apresentada. Alguns participantes sugeriram que essa lista deveria ser apresentada por prioridade do usuário ou frequência de uso, como faz o sistema C, ao invés de em ordem alfabética.

\section{Conclusão}

Pode-se concluir, portanto, que problemas de usabilidade ainda ocorrem em sistemas de navegação GPS. Com o que foi observado e analisado na aplicação do teste, pôde-se constatar que vários princípios de usabilidade (BASTIEN; SCAPIN, 1993; NIELSEN, 1994; SHNEIDERMAN, 1998; JORDAN, 1998; NORMAN, 2002) não foram atendidos nos projetos das interfaces dos três navegadores avaliados. Observa-se que a maioria dos problemas encontrados está relacionada à apresentação das informações do sistema e à interação do usuário nas várias etapas para a execução de tarefas típicas de entrada de dados. Em uma visão geral, com as tarefas que foram analisadas, pode-se dizer que os problemas de projeto encontrados ora estão associados à entrada de dados de endereço, no caso da tarefa 1 - definir destino por endereço, ora estão associados à navegabilidade dos sistemas, como é o caso dos problemas encontrados na tarefa 2 selecionar como destino o posto de gasolina (POI) mais próximo do sinal GPS.

Quanto à entrada de dados do endereço, foi verificado que essa atividade deve ser feita em etapas e com filtros dos nomes das vias. Pode-se concluir que inserir um endereço é mais eficaz, eficiente e rápido quando a tarefa é executada em etapas curtas e sequenciais, com o auxílio do navegador (os filtros) e com informações constantes (default) que possam ser estabelecidas de antemão, como determinar a cidade do endereço. Dessa forma, a tarefa se torna mais segura de ser realizada com o automóvel em movimento.

Para a execução da tarefa de selecionar um ponto de interesse como destino, fica evidente que a seleção da categoria de pontos de interesse é a questão mais problemática para uma execução rápida e segura quando são consideradas longas listas de opções. Nesse caso, o sistema C mostrou-se o melhor projeto para a seleção das categorias, que são apresentadas por prioridade, ou seja, as mais usadas pelo usuário são as que aparecem primeiro no momento da seleção.

Em navegadores GPS deve-se evitar o uso de listas, principalmente por causa do tamanho dos displays, ainda mais para esse tipo de tarefa que é realizada com frequência nesse tipo de sistema. Obviamente, existirão momentos em que o uso de uma lista deverá acontecer, tanto porque o usuário pode querer uma outra categoria quanto por causa do vasto banco de dados que esses 
sistemas possuem. Porém, deve-se minimizar ao máximo o uso dessas listas e, caso seja necessário apresentá-las, estas devem ser pequenas, com as opções mais agrupadas.

Os esquemas (wireframes) demostrados nas Figuras 14 e 15 apresentam sequências de telas ideais e recomendadas tanto para a inserção de dados do endereço (tarefa 1 - Figura 14) quanto para a seleção de um ponto de interesse como destino (tarefa 2 - Figura 15) em sistemas de navegação GPS.

Este artigo apresenta apenas alguns resultados da pesquisa. Outras tarefas foram testadas, assim como outras técnicas foram aplicadas em Quaresma (2010).

\section{Referências}

ALLIANCE OF AUTOMOBILE MANUFACTURERS. Statement of principles, criteria and verification procedures on driver interactions with advanced in-vehicle information and communication systems. Washington, D.C.: Alliance of Automobile Manufacturers, 2003.

BASTIEN, J. M. C.; SCAPIN, D. Ergonomic criteria for the evaluation of human computer interfaces. Le Chesnay: INRIA, 1993.

BRANGIER, É.; BARCENILLA, J. Concevoir un produit facile à utiliser. Paris: Éditions d'Organisation, 2003.

BRASIL. Conselho Nacional de Trânsito - CONTRAN. Resolução $n^{\circ}$ 153, de 17 de dezembro de 2003. Diário [da] República Federativa do Brasil, Brasília, DF, 26 dez. 2003.

BRASIL. Conselho Nacional de Trânsito - CONTRAN. Resolução $n^{\circ}$ 190, de 16 de fevereiro de 2006. Diário [da] República Federativa do Brasil, Brasília, DF, 01 mar. 2006. Seção 1, p. 61.

BRASIL. Conselho Nacional de Trânsito - CONTRAN. Resolução $n^{\circ}$ 242, de 22 de junho de 2007. Diário [da] República Federativa do Brasil, Brasília, DF, 04 jul. 2007. Seção 1, p. 109.

DUMAS, J.; LORING, B. Moderation usability tests - principles \& practices for interaction. Burlington: Morgan Kaufmann Publishers, 2008
EUROPEAN COMMUNITIES. Recommendations on safe and efficient in-vehicle information and communication systems: update of european statement of principles on human machine interface. Brussels: European Union, 2008. Official Journal 2008/653/EC.

INTERNATIONAL ORGANIZATION STANDARDIZATION. Ergonomic requirements for office work with visual display terminals (VDTs) -- Part 11: Guidance on usability. Génève: 1SO, 1998.

JAPAN AUTOMOBILE MANUFECTURERS ASSOCIANTION JAMA. Guidelines for in-vehicle display systems. Tokyo: JAMA, 2000.

JORDAN, P. W. An introduction to usability. London: Taylor \& Francis, 1998.

NIELSEN, J.; MACK, R. L. Usability inspection methods. New York: John Wiley \& Sons, 1994

NOEL, E.; NONNECKE, B.; TRICK, L. A comprehensive learnability evaluation method for in-car navigation devices. In: SAE WORLD CONGRESS, 2005. Proceedings... Detroit: SAE International, 2005a.

NOEL, E.; NONNECKE, B.; TRICK, L. Evaluating first-time and infrequent use of in-car navigation devices. In: INTERNATIONAL DRIVING SYMPOSIUM ON HUMAN FACTORS IN DRIVER ASSESSMENT, TRAINING AND VEHICLE DESIGN, 3., 2005. Proceedings... Rockport: University of lowa/PPC, 2005b.

NORMAN, D. The design of everyday things. New York: Basic Books, 2002.

NOWAKOWSKI, C.; GREEN, P.; TSIMHONI, O. Common automotive navigation system usability problems and a standard test protocol to identify them. In: ITS-AMERICA 2003 ANNUAL MEETING, 2003. Proceedings... Washington DC: Intelligent Transportation Society of America, 2003.

QUARESMA, M. Avaliação da usabilidade de sistemas de informação disponíveis em automóveis: um estudo ergonômico de sistemas de navegação GPS. 2010. 340 f. Tese (Doutorado em Design)-Pontifícia Universidade Católica do Rio de Janeiro, Rio de Janeiro, 2010.

RUBIN, J.; CHISNELL, D. Handbook of usability testing - how to plan, design and conduct effective tests. $2^{\text {nd }}$ ed. Indianapolis: Wiley Publishing, 2008.

SHNEIDERMAN, B. Designing the user interface. $3^{\text {rd }}$ ed. Massachusetts: Addison-Wesley, 1998. 639 p.

SOCIETY OF AUTOMOTIVE ENGINEERS. Navigation and route guidance function accessibility while driving. Warrendale: SAE International, 2004. SAE Recommended Practice J2364.

\title{
The usability of typical tasks of destination selection in automotive GPS navigation systems
}

\begin{abstract}
The automotive GPS navigation system is an in-vehicle system that helps drivers find their way to their destination through maps and maneuvering indicators. This article presents a study on the usability of typical tasks of destination selection in three navigation systems sold in Brazil, with different data entry methods and interfaces. The research aimed to calculate the occurrence of usability problems in navigators in Brazil. Usability tests were applied to both experienced and non-experienced users in order to measure the effectiveness, efficiency and use satisfaction (usability metrics) of the three interfaces. With the tests results, several usability issues were observed in the design of the interfaces evaluated and appropriate solutions were suggested to the organization and navigation of menus and commands.
\end{abstract}

\section{Keywords}

Gps navigation systems. Usability. Human-computer interaction. Ergodesign. 